Organo- and

Organocatalytic Asymmetric Biomimetic Transamination: From $\alpha$-Keto Esters to Optically Active $\alpha$-Amino Acid Derivatives

J. Am. Chem. Soc. 2011, 133, 12914-12917.

\title{
Synthesis of $\alpha$-Amino Acid Derivatives by Biomimetic Transamination
}<smiles>[R]C(=O)OCC</smiles>
$\mathrm{H}_{3} \mathrm{O}^{+}$

$\mathrm{R}=\mathrm{Ar}$, Alk<smiles>[R]C(N)OCC</smiles>

22 examples $47-71 \%$ yield er $=94: 6$ to $96: 4$

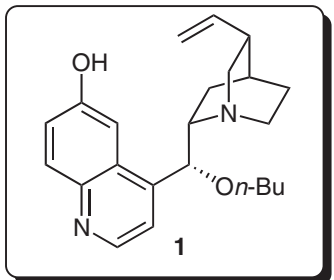

Plausible mechanism of the biomimetic transamination and proposed transition state:
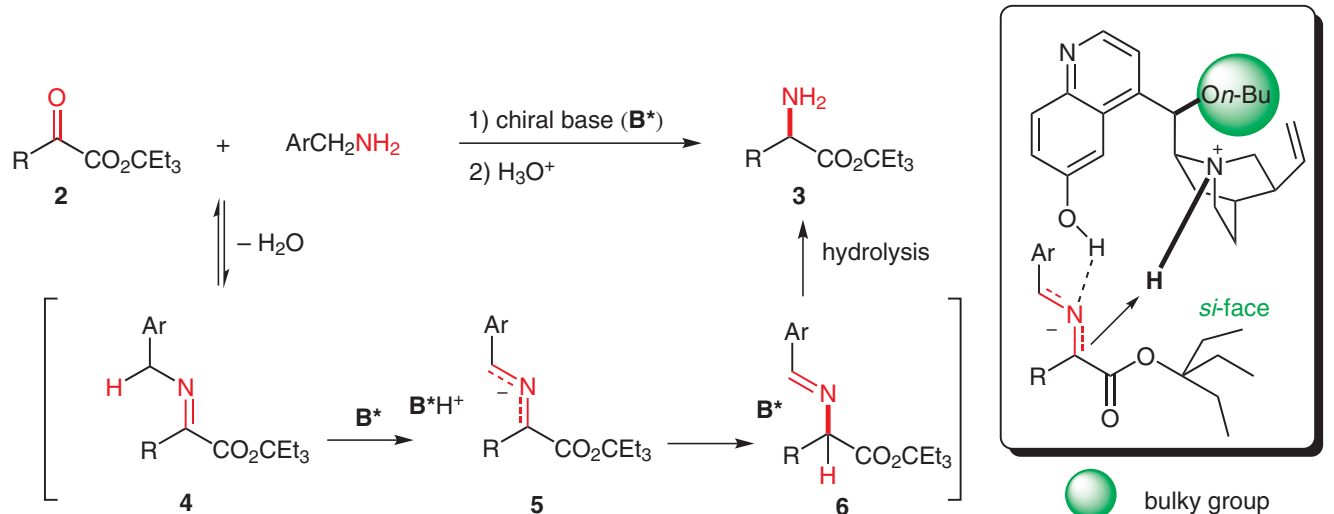

Significance: Shi and co-workers have developed a methodology to synthesize $\alpha$-amino acid derivatives $\mathbf{3}$ from $\alpha$-keto esters $\mathbf{2}$, catalyzed by cinchona alkaloid derivative $\mathbf{1}$. This is the first catalytic highly enantioselective synthesis of $\alpha$-amino acid derivatives $\mathbf{3}$ via biomimetic transamination. The proton of the ammonium ion in the transition state is delivered to the si-face of the substrate, affording the $(R)$ - $\alpha$-amino ester as the major enantiomer.
Comment: Optically active $\alpha$-amino acids and their derivatives are an important class of molecules in biology and in organic synthesis. However, it remains a challenge to develop highly enantioselective syntheses of them to date. Here, a very efficient method for the synthesis of $\alpha$-amino acid derivatives via biomimetic transamination has been reported, which also illustrates the synthetic potential of organocatalytic biomimetic transamination.

SYNFACTS Contributors: Benjamin List, Qinggang Wang 